\title{
(息)
}

Citation:

Long, J (2018) Classic book review: Coal is Our Life. Annals of Leisure Research. ISSN 1174-5398 DOI: https://doi.org/10.1080/11745398.2018.1530303

Link to Leeds Beckett Repository record:

https://eprints.leedsbeckett.ac.uk/id/eprint/5664/

Document Version:

Article (Accepted Version)

This is an Accepted Manuscript of an article published by Taylor \& Francis in Annals of Leisure Research on 05 October 2018, available online: http://www.tandfonline.com/10.1080/11745398.2018.1530303

The aim of the Leeds Beckett Repository is to provide open access to our research, as required by funder policies and permitted by publishers and copyright law.

The Leeds Beckett repository holds a wide range of publications, each of which has been checked for copyright and the relevant embargo period has been applied by the Research Services team.

We operate on a standard take-down policy. If you are the author or publisher of an output and you would like it removed from the repository, please contact us and we will investigate on a case-by-case basis.

Each thesis in the repository has been cleared where necessary by the author for third party copyright. If you would like a thesis to be removed from the repository or believe there is an issue with copyright, please contact us on openaccess@leedsbeckett.ac.uk and we will investigate on a case-by-case basis. 


\section{Classic Book Review}

Long.J

Dennis, N., Henriques, F. and Slaughter, C. (1956) Coal is Our Life. London: Eyre and Spottiswoode. ${ }^{1}$

Despite living less than 20 miles away from Featherstone, until I started to write this review I had only been there once. Featherstone is the Ashton of Coal is Our Life, and its population now of some 15,000 is similar to what it was in the 1950 s. Today there is less pollution, and the last of the outside toilets have gone, but crucially, gone too are the mines and even the slag heaps, levelled to provide space for new 'industrial parks' and warehousing. Of course, the mines have not just gone from Featherstone they have gone from the whole of Yorkshire. At nationalisation of the mines in 1947 there were 137 mines in Yorkshire; at the time of the Miners' strike in 1984/5 there were 56; today there are none. That has also meant the demise of the Miners' Welfare Institute and some of the Miners' allotments, and the Featherstone Miners Welfare sport pitches are now run by the local authority.

In the introduction to the second edition (1969) Henriques (rhetorically) questions the continuing relevance of Coal is Our Life. Fifty years later again, let me do the same as I offer some observations on its relationship to leisure research. From the title of the book it may not be obvious why I should think it has anything to tell us about leisure. It sits among a suite of community studies that go at least as far back as the Lynds' (1929) study of Middletown, and, like many such studies, recognises the significance of leisure in the lives of the community. Indeed, leisure is one part of the threefold structuring device for the book, along with work and family, set within the context of place. These were the same three planes that the Rapoports (1975) used two decades later to make sense of leisure and the family life cycle. Dennis, Henriques and Slaughter thoughtfully address the intersections of these planes, and although there is a desire to impose a certain homogeneity that appears excessive from this vantage point, they also identify some generational differences and are particularly powerful in demonstrating the very different lives of men and women in Ashton.

Given the choice of a town so dominated by a single industry as the subject of the community study, it is hardly surprising that so much attention is given to the consequence of work patterns for the inhabitants' leisure lives. In this it acts as a precursor to the debates about the relationship between work and leisure that were so significant in the development of leisure studies in the 1970s (see, for example, Spracklen's (2017) review of Parker's work in an earlier issue of the Annals of Leisure Research). A 1920 law required the coalmining industry to provide leisure facilities. In addition to funding the brass band, in Ashton this took the form of allotments, sports pitches and the Welfare Institute with its working men's club and theatre. The Institute offered a wide range of activities, but the authors observe that it did not play much part in the lives of those over 20 who preferred the working men's clubs of the town.

\footnotetext{
${ }^{1}$ Any page numbering here come from the $2^{\text {nd }}$ edition published by Tavistock in 1969.
} 
However, the influence of work was seen to go far beyond just that provision. Not only did the structure of work, in the shape of shift patterns, disrupt band rehearsals and performances as well as sports training and fixtures, but it shaped attitudes engendered in a community dominated by the one industry for a century. The authors identified the pursuit of leisure in Ashton as being 'vigorous and frivolous' (p130) and this they attributed to attitudes consequent upon the danger of death and the threat of loss of income due to injury (they also identified an escapist function offered by the choice of reading and cinema going). Although the study was conducted while employment in mining was reasonably well paid (compared with similar work available for the same qualifications) and reliable, the insecurity of earlier times had left its mark on mining families such that they tended to keep their general standard of living low. Then if they did have a period of good income it was spent freely by the men on drinking and gambling. Leisure provision in Ashton was structured for men: clubs, pubs, sports facilities and gambling. In addition to being escapist, leisure in Ashton then was characterised by the safety of the familiar. Today there is still a local travel agent offering coach trips to Rhyl and Blackpool, a model railway shop and a sign in the window of the newsagent advertises 'bingo dabbers' (bingo being the housey-housey of 1950s Ashton)

The social consequences of living and working alongside the same people established a powerful community culture, one of the consequences of which was that the strong separation of men and women enforced by employment in mining was reproduced in their leisure lives. The authors express this unequivocally when they talk of 'the exclusion of women from these activities in Ashton which are outside of work and the family' (p203 emphasis added) ${ }^{2}$. They explain that the men:

...grow into a set of attitudes and ideas which very consciously exclude women from the activities and permitted liberties of the male group, which can be said to constitute a type of secret society. (p211)

Having established that the proportion of women in the workforce, although slowly increasing, was strikingly low, they identify the dominant assumption in Ashton that the woman's place is in the home. It is partly this that the second wave feminists appear to have objected to (Crow, 2012). However, this was not the view of the authors. Rather, I have little doubt it represented an unemotional account of what they found to be the dominant view in Ashton in the 1950s.

The authors observe (p.170/1):

"A man's centres of activity are outside his home... He works, plays and makes contact with other men and women outside his home ... the husbands of Ashton for preference come home for a meal after finishing work and as soon as they can feel clean and rested they look for the company of their mates" (emphasis in the original).

\footnotetext{
${ }^{2}$ They recognise this to be different from the larger town nearby.
} 
The division of housework implicit here will be familiar to today's feminist leisure scholars or those who read the reports from the British Social Attitudes Survey. The position may have ameliorated somewhat in that by 2012 only 13\% of the population agreed with the statement that 'A man's job is to earn money; a woman's job is to look after the home and family' (Scott and Clery 2012), but later the report notes that 'both men and women agree that women spend much more time each week on average both on household work and on looking after family members' (almost twice as much).

Despite their use of employment and other statistics, and their own survey, Dennis, Henriques and Slaughter were criticised for being overly dependent on anecdote. This seems to be less true of Coal is Our Life than it was of the vaunted Family and Kinship in East London published the following year (Young and Wilmott, 1957). Coal is Our Life has a more critical edge provided by an appreciation of the ways in which economic and political forces structure social relations. These structural elements help to ameliorate criticisms of community studies more generally. Where anecdote felt most intrusive to me was in the stories reported from some of the miners which had more than a hint of braggadocio, but the authors are simply reporting something that reflects the behaviour of some men in that community, behaviour not dissimilar to that of Blackshaw's (2003) 'lads' only a few miles away nearly half a century later. Both works illustrate the pressure to be 'one of the lads' in an environment where sexism is the norm.

For an all-male research team supposedly dependent on anecdote they seem to have developed a high degree of rapport and trust with women in the community, who were prepared to share intimacies of unsatisfactory sex lives and self-induced abortions. And despite the observations about being tied to the home, they did comment on the political involvement (though without political power) of some of the women. Whereas the Labour Party met only 4-6 times a year the women's section met fortnightly (yet I recall the effort it took to establish women's sections in the Labour Party in the 1980s) and the authors observe:

In any particular strike if it comes to the question of solidarity the wives usually defend their menfolk strongly; they share the sense of injustice felt by miners and defend their husbands against the enemy. (p.227)

And so it proved in the 1984/5 Miners' Strike when Women Against Pit Closures played such a key role.

The argument developed in the book reflects a cultural determinism that is unlikely to make it popular with post-modernists. This is evidenced in various ways, for example through the consequences work has for leisure:

'If the form of leisure activity is a consequence of mining, so is its content. We have suggested that the essentially frivolous character of leisure in Ashton is closely related to the insecurity, both physical and social, produced in the past and present by coalmining as an occupation in Britain.' (p248) 
And both men and women were seen to be shaped by pressures to conform and the dominant ideology. Of the constrained position of women, they say: 'The ideas of what a woman should and should not do persist very strongly, and, of course, they are values accepted by the women themselves' (p202). This sits alongside the set of men's attitudes that exclude women from leisure society. While some of those limitations may have eased in subsequent generations readers of Foucault will recognise the difficulty of escaping the surveillance of the collective gaze within the community.

As one who dissents from the view that class is a zombie construct I could recognise what Dennis, Henriques and Slaughter had to say about the strictures of class, even how the mark of class determined the educational opportunities of children. This, after all, was what lay at the heart of Sure Start and the suite of educational policies introduced by New Labour in the UK around the millennium.

As implied above, Coal is Our Life has been the subject of some criticism. For example, when Warwick and Littlejohn (1992) did their re-study they suggested that the original had been overly romantic, reliant on anecdote, imposing an excessive homogeneity and dismissive of women, and that the authors brought their preconceived stereotypes with them. No doubt some of those criticisms are true to some extent, but let those without sin cast the first stone; and in any case I find much in the book that rings true and I certainly do not find it an account lacking a critical perspective. In the social sciences we have arrived at a more sophisticated appreciation of subjectivity.

Like Hoggart's (1957) Uses of Literacy, parts of the book seem to be addressing what was already past. Society clearly changes. Since 1956, patterns of employment have undoubtedly changed. The days when $60 \%$ of families could be dependent on colliery (or any other single industry) wages, with many more in ancillary activities, are long gone. Family structure and attitudes have changed too and the home has become a more significant leisure space. Clearly the authors got some things wrong, like questioning that any house should need more than one television. Nonetheless, just as they showed, the invisible hand still manages to signal that certain leisure spaces are not for women. Importantly too, given the recent popularity of highly individualised theories of leisure, reading Coal is Our Life provides a reminder that leisure practices are founded in social relations and cannot be understood independent of dominant political and economic forces.

\section{References}

Blackshaw, T. (2003) Leisure Life: myth, masculinity and modernity. London: Routledge.

Crow, G. (2012) Community re-studies: lessons and prospects. Sociological Review, 60(3), 405-20.

Hoggart, R. (1957) The Uses of Literacy. London, Chatto \& Windus.

Lynd, R. and Lynd, H. 1929 Middletown: A Study in Contemporary American Culture. New York: Harcourt, Brace, and Company, 
Rapoport, R. and RN. (1975) Leisure and the Family Life Cycle. London: Routledge and Kegan Paul.

Scott, J. and Clery, E. (2013) Gender Roles. In Park, A., Bryson, C., Clery, E., Curtice, J. and Phillips, M. (eds.), British Social Attitudes: the 30th Report. London: NatCen Social Research. [Available online at: www.bsa-30.natcen.ac.uk]

Spracklen, K. (2017) The future of work and leisure. Annals of Leisure Research, 20(3), 394396.

Warwick, D. and Littlejohn, G. (1992) Coal, Capital and Culture: A sociological analysis of mining communities in West Yorkshire. London: Routledge.

Young, M. and Willmott, P. (1957) Family and Kinship in East London. London: Routledge and Kegan Paul.

Jonathan Long, Leeds Beckett University, UK (J.A.Long@leedsbeckett.ac.uk) 